\title{
TUBERCULOSIS AND HUMAN RIGHTS
}

Many of the factors that increase a person's vulnerability to tuberculosis (TB) or reduce their access to services to prevent, diagnose and treat TB are associated with their ability to realize their human rights. A human rights-based approach to TB prevention, treatment and care can help programme managers, civil society and other TB partners overcome the many barriers to effective TB prevention, treatment and care.

This briefing note offers an introduction to TB; human rights; the rights issues that affect TB prevention, treatment and care; and the TB and Human Rights Task Force, established to develop a policy framework for a human rightsbased approach to TB prevention, diagnosis, treatment, care and support.

\section{TUBERCULOSIS}

- One third of the world's population is infected with the airborne bacillus that causes tuberculosis (TB) disease.

- One in every 10 of those who are infected will become sick with active TB disease. If immuno-suppressed, the risk of developing active TB disease is much higher.

- Over 9 million people fell ill and 1.7 million people died from TB in 2009, including nearly 600,000 women. The vast majority of deaths occur in developing countries.

- TB is a leading killer among people living with HIV, accounting for $26 \%$ of HIVassociated deaths worldwide.

- In 2009 there were 440,000 MDR-TB cases (3,3\% of all new cases), and MDR-TB caused 150000 deaths.

TB is deeply rooted in poverty. Poverty and low socioeconomic status as well as legal, structural and social barriers prevent universal access to quality TB prevention, diagnosis, treatment and care. The promotion and realization of human rights is essential to overcome these barriers, diminish peoples' vulnerability to TB and ensure an effective response to TB as well as to achieve the Millennium Development Goals and increase impact on health, development and human rights more broadly.

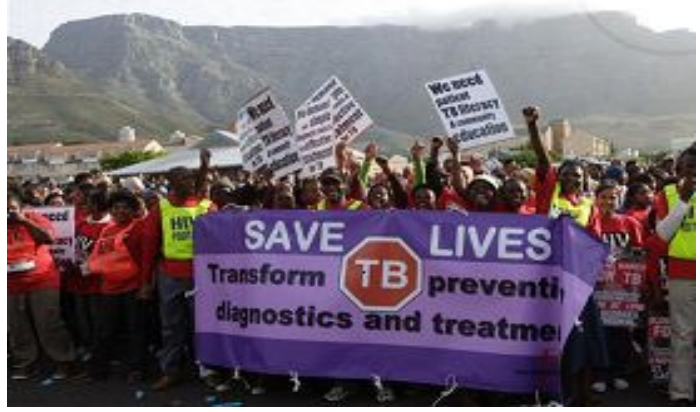

Activism for TB prevention and care
The protection and promotion of human rights in TB prevention, care and control is a key objective of the Stop TB Strategy.

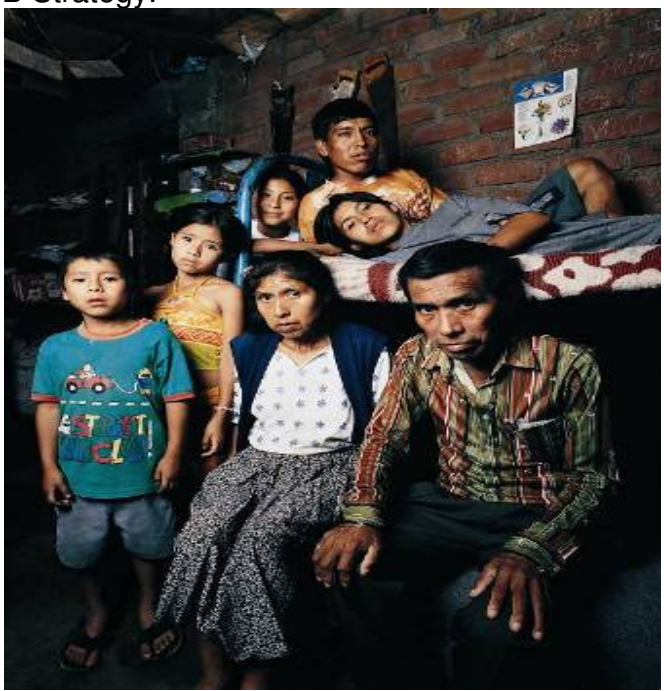

A family affected by MDR TB

Human Rights are:

- Universal and inalienable - they belong to every human being and cannot be taken away

- Interdependent and indivisible - they are all necessary for the dignity of human persons and every human right is often dependent upon the realization of other human rights

- Articulated as set of entitlements generating obligations on States to respect, protect and fulfill - States have to refrain from interfering with the enjoyment of the right, prevent others from interfering and adopt appropriate measures towards the full realization of the rights

- Internationally guaranteed and legally protected - they are recognized in international human rights treaties that States have ratified

The Right to Health

- The right to health comprises the right to access to health facilities, goods and services, to healthy occupational and environmental conditions, and protection against epidemic diseases and rights relevant to sexual and reproductive health.

- The right to health is dependent on and contributes to the realization of many other human rights. It includes a wide range of factors, the "underlying determinants of health" such as safe drinking water, food, adequate nutrition, housing, healthy occupational and environmental conditions, education etc.

- The right to health calls for immediate and targeted steps as well as for steps to be taken progressively in order to ensure that health services, goods and facilities are available, accessible, acceptable and of good quality. 


\section{A HUMAN RIGHTS-BASED APPROACH TO TB}

The following are principles for a human rights-based approach to TB, building on the "UN Common Understanding on a Human Rights-based Approach":

- Person and affected communities placed at the centre, as equal partners, driving health policy, providing the individual and groups with the tools to participate and claim specific rights

- The most marginalized, at risk and vulnerable identified, informed and empowered, to access TB prevention, treatment and care

- Dignity assured for patients and those affected

- Socio-economic determinants of TB addressed

- Human rights implications of TB policy, legislation and programming addressed

- Institutional constraints and capacity gaps that prevent individuals and groups from fulfilling their rights related to TB overcome

- Integrated and multisectoral response to TB supported making human rights an integral dimension in the design, implementation, monitoring and evaluation of TB related policies and programmes

- Accountability tools provided for governments, the international community and civil society to monitor the progress of all stakeholders in realizing the right to health

- Platform provided for documenting and sharing best practices, supporting advocacy and social mobilization around human rights relevant to TB

Figure 1: Links between human rights, preventing TB, and increasing access to TB care and support

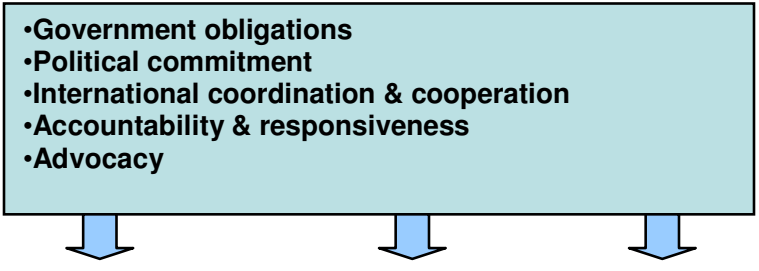

Preventing vulnerability to TB

-Right to non discrimination

-Right to health

-Right to work

-Right to adequate housing

-Right to adequate food

-Right to safe drinking water \& sanitation

- Right to education

-Right to information

Increasing access to quality TB diagnosis,

treatment, care and support

-Right to non discrimination

-Right to access to health services and essential drugs

- Right to participation

-Right to information

- Right to education

- Right to social security and financial protection

-Right to privacy

- Freedom of movement

-Right to body integrity and freedom from torture and

inhuman or degrading treatment

- Right to due process protection

- Siracusa principles

-Right to enjoy the benefits of scientific progress and its applications"

\section{ACHIEVE RESULTS}

-Reduced vulnerability

-Increased access to effective TB prevention, diagnosis, treatment, care and support

-Empowerment of individuals \& communities

-Enhanced capacity building and development 


\section{Human rights issues associated with TB - to be addressed in the Task Force's policy framework}

\section{Preventing TB}

- Many economic, social and cultural rights are strongly interlinked (e.g. lack of education, poor nutrition, poor housing and sanitation, lack of access to quality health services and facilities, lack of employment and social security) and affect people's vulnerability to contract TB. Being ill with TB also increases vulnerability to poverty.

\section{Access to care}

- Effective diagnosis is often hindered by costs, lack of social security or health services, and other barriers associated with seeking care, such as stigma and discrimination, or lack of information and specific public policies.

- Poor quality of care and lack of drug supplies hamper global TB control efforts. Inadequate diagnostic tests and limited resources inhibit early detection resulting in increased transmission and poor health outcomes. The TB detection rate was $63 \%$ in 2009 .

- In 2009, there were an estimated 0.38 million deaths among TB incident cases who were HIV positive. Early diagnosis among people living with HIV is challenging but vital. In 2009 , only $5 \%$ of people living with HIV were screened for TB.

- Drug-resistant TB (M/XDR-TB) is man-made. It is associated with poor prescribing, irregular drug supply, inadequate access to quality care, and adherence problems. It does not respond to standardized treatment with first-line drugs. Treatment is long, expensive, uncomfortable and onerous for the patient - often with no option but forgoing family life for $1 / 2$ to 2 years.

- Accessing care can lead to catastrophic expenditures which may contribute to impoverishment for the individual and his or her entire family.

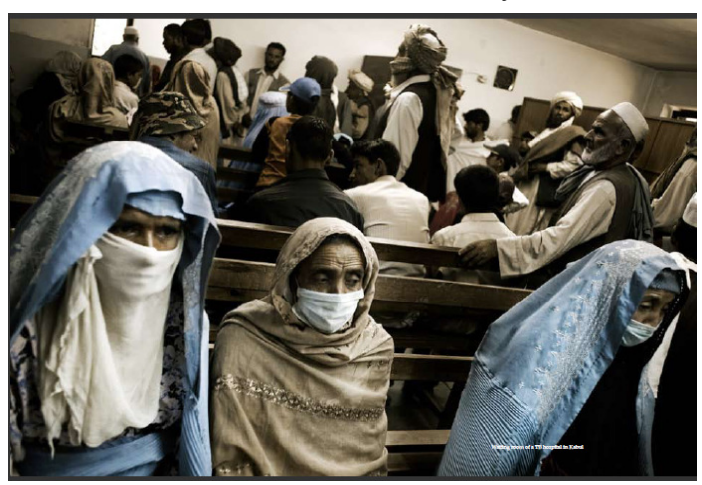

Women waitina for care in a health centre

\section{Women}

- TB is among the top three causes of death among women aged 15-44. The 'feminization' of the HIV epidemic has meant an ever greater burden of TB among women. Maternal TB/HIV is an important risk factor for pediatric TB and maternal and child mortality.

- TB can cause infertility if latent bacilli get reactivated and infect the genital tract. Genital TB is always hard to diagnose because of the absence of specific symptoms.

- TB-related stigma and discrimination affect women's access to health care, delaying seeking care.

\section{Prisoners and detained persons}

- Data suggest that TB is the leading cause of death among the world's prisoners.

- Poor prison conditions including overcrowding, poor ventilation, hygiene and nutrition- favor TB transmission and reactivation. Adequate care may be denied.

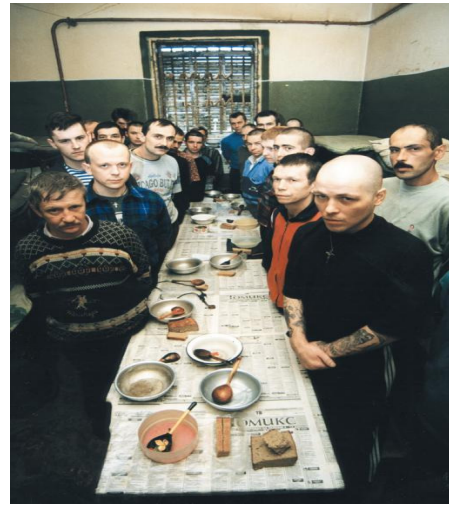

Overcrowded prison where TB can spread easily

\section{Children}

- The diagnosis of TB is difficult due to non-specific symptoms and problems in confirming the diagnosis.

- Treatment is challenging due to the lack of childfriendly formulations and difficulties in monitoring toxicity.

- In addition to suffering from TB directly, children are severely affected as well as orphaned due to TB among their parents. Children ill with TB are often taken out of school for prolonged period of time, hence their right to education is often also at stake.

- Vulnerable children and youth, such as street children face significant risk of contracting TB associated to poor housing, poor nutritional status, lack of access to care, education and information.

\section{Work place}

- Poor working conditions can greatly exacerbate TB transmission, such as in health care settings, prisons, mines and factories.

- TB diagnosis or a history of TB may lead to loss of work, or inability to get work. People ill with TB may face the tradeoff of pursuing treatment or maintaining their job.

\section{Migrants}

- Migrants in irregular situations often fall to the lower end of the social structure where they may be at risk of TB through poor housing, inadequate nutrition or lack of access to health facilities, information and services., exploitative working conditions

- Migrants may be denied access to diagnosis and treatment for TB because of their legal status. They may avoid accessing health services for fear of deportation and delay seeking treatment because of lack of education and information.

- Continuity of care is often unavailable to forcibly returned migrants. 


\section{Refugees}

- High risk of developing TB associated to poor nutritional status and sanitation, stigma, crowded living conditions, poor access to care, education and information and other coexistent illness. Lack of legal status can increase refugees' vulnerability to TB and may lead to denial of services, access to information and education

- Ensuring appropriate TB treatment and control may be difficult due to changing emergency situations and labile refugee population.

\section{Internally displaced people}

- TB Prevention, diagnostic and continuity of care is often neglected in the context of protracted humanitarian emergencies

\section{Indigenous peoples}

- High TB rates and lack of access to care compounded by poverty, discrimination, poor education inadequate nutrition and housing.

\section{People who use drugs}

- TB risk is increased in people who use drugs regardless of HIV status.

- Drug use is often associated with poverty, discrimination, criminalization of drugs, unemployment, homelessness and lack of access to social services.

\section{People who use alcohol}

- The harmful use of alcohol is a significant risk factor for TB. Treatment may be wrongly denied due to a perceived potential for individuals to drop-out of care.

\section{Patients involuntarily detained}

- Involuntary detention and/or treatment may be imposed for persons being tested or treated for TB without due process or justification, inhibiting rights and carrying important social and economic impacts.

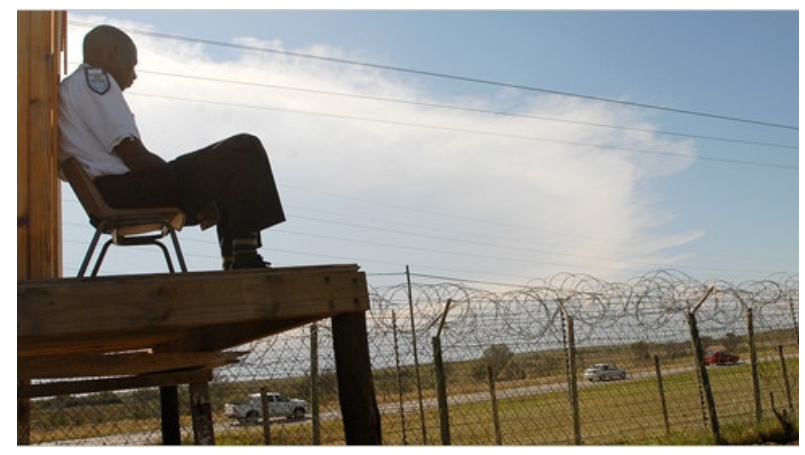

A guard at an MDR-TB hospital

\section{Stop TB Partnership Human Rights and TB Task Force}

In order to advance a rights- based approach to TB prevention, care and support, the Stop TB Partnership has established a TB and Human Rights Task Force. The Task Force comprises representatives of major stakeholder constituencies from affected communities and risk groups, UN agencies, human rights organizations, civil society organizations, health and human rights experts and development partners.

Aim: to advance the protection and promotion of human rights, in pursuit of universal access to TB prevention, diagnosis, treatment, care and support so as to advance health, development and effective TB response, including for the most vulnerable, through the implementation of rights-enhancing policies, strategies and programming.

\section{Task Force objectives:}

1. Develop an evidence-based policy framework for a rights-based approach to TB prevention, diagnosis, treatment, care and support

2. Develop and implement a strategic agenda to pursue a rights-based approach through a wide range of stakeholders

3. Mainstream human rights approach in Stop TB Strategy, Global Plan and Stop TB efforts

4. Advocate for adoption by other constituencies beyond TB

5. Mobilize resources

6. Monitor and evaluate first actions

This work is aligned with the new WHO 'Guidance on ethics of tuberculosis prevention, care and control' http://www.who.int/tb/features archive/ethics/en/index.html

\section{Secretariat Contacts:}

Diana Weil (WHO) weild@who.int

Alasdair Reid (UNAIDS) reida@unaids.org

Task Force website: http://www.stoptb.org/global/hrtf/ 


\section{Some Key References}

\section{Human rights documents}

- Universal Declaration of Human Rights (1948) http://www.un.org/en/documents/udhr/

- International Covenant on Economic, Social and Cultural Rights (1966)

http://www2.ohchr.org/english/law/cescr.htm

- International Covenant of Civil and Political Rights (1966). http://www2.ohchr.org/english/law/ccpr.htm

- Committee on Economic, Social and Cultural Rights, General Comment No. 14 http://www.unhchr.ch/tbs/doc.nsf/(symbol)/E.C.12.2000.4.En

- Committee on Economic, Social and Cultural Rights, General comment No. 20 on non discrimination in economic, social and cultural rights,

- http://www2.ohchr.org/english/bodies/cescr/comments.htm

- Convention on the Rights of the Child (1989) http://www2.ohchr.org/english/law/crc.htm

- Convention on the Elimination of All Forms of Discrimination Against Women (1979) http://www.un.org/womenwatch/daw/cedaw/

- International Convention on the Elimination of All Forms of Racial Discrimination (1963) http://www2.ohchr.org/english/law/cerd.htm

- Convention on the Rights of Migrant Workers (1990) http://www2.ohchr.org/english/law/cmw.htm

- Declaration of Alma Ata (1978) http://www.who.int/hpr/NPH/docs/declaration almaata.pdf

- Siracusa principles: http://www1.umn.edu/humanrts/instree/siracusaprinciples.html

- Special Rapporteur on the Right to Health (2002): http://www2.ohchr.org/english/issues/health/right/

\section{TB-related documents}

- WHO Stop TB Strategy: http://www.who.int/tb/strategy/en/index.html

- Updated Global Plan to Stop TB, 2011-2015:

http://www.stoptb.org/assets/documents/global/plan/TB GlobalPlanToStopTB2011-2015.pdf

- Global Plan to Stop TB, 2006-2015:

http://www.who.int/tb/features archive/global plan to stop tb/en/index.html

- UNAIDS Strategy (including TB/HIV):

http://www.unaids.org/en/media/unaids/contentassets/documents/unaidspublication/2010/JC2034 UNAIDS Strategy en.pdf

- Patients' charter: http://www.who.int/tb/publications/2006/patients charter.pdf

- Social determinants and TB: http://whqlibdoc.who.int/publications/2010/9789241563970 eng.pdf

- Poverty and TB:

http://www.who.int/tb/challenges/poverty/en/index.html

- TB in Prisons:

http://www.who.int/tb/challenges/prisons/en/index.html

- TB care and control in refugees and displaced populations: http://www.who.int/tb/challenges/refugees/en/index.html

- Women and TB: http://www.who.int/tb/womenandtb.pdf

- Union statement on TB among undocumented migrants: http://www.theunion.org/images/stories/download/guide/Undocumented-migrantsStatement 2008.pdf

- Guidelines for social mobilization. A human rights approach to TB:

http://www.who.int/hhr/information/A\%20Human\%20Rights\%20Approach\%20to\%20Tuberculosis.pdf

- Community involvement in TB:

http://www.who.int/tb/people and communities/involvement/resources/en/index.html

- Active engagement of civil society organizations http://whqlibdoc.who.int/hq/2010/WHO HTM TB 2010.15 eng.pdf

\section{Health and Human Rights documents}

- WHO Health and Human Rights/Department of Ethics, Equity, Trade and Human Rights: www.who.int/hhr/

- HIV and human Rights:

http://data.unaids.org/Publications/IRC-pub07/jc1252-internguidelines en.pdf http://www.unaids.org/en/PolicyAndPractice/HumanRights/20070601 reference group

- TB/HIV and human Rights: http://data.unaids.org/pub/ExternalDocument/2010/20100324 unaidsrghrtsissuepapertbhrts en.pdf 